$$
\begin{aligned}
& \text { نوران عصام نبل محمد أنماء }
\end{aligned}
$$

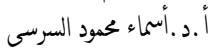

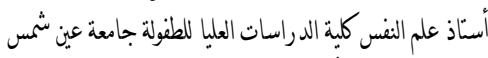

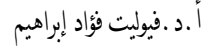

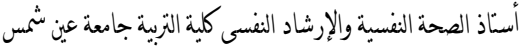

الشعلة: تتحدد مشكلة الدر اسة فى السؤ ال الرئس التالي: ما فاعلية برنامج تدريبى لتتبية الوعى بالجسم لدى فئة من الأطفال الذاتوبين؟ وينبق من هذا السؤال الرئبس الأسئلة الآتية هل توجد فروف بين منوسطات رتب درجات المجموعة (التجريبية- الضابطة) فى القباسين قبل إجر اءات البرنامج وبعده على مقاس الوعى بلى بالجس؟؛

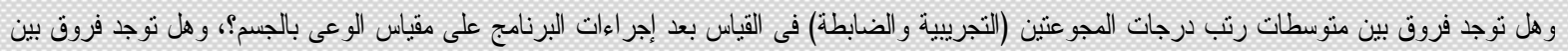

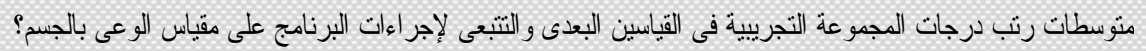
الهدف: هدفت هذه الدر اسة إلى الكثف عن فاعلية البرنامج التدريبى فى تتمية الوعى بالجسم لاى عبنة من الأطفال الذانويين والتحقق من مدى استمر ارية تأثير البرنامج في تتمبة الوعى بالجسم لاى المجهو علهة التجريبية.

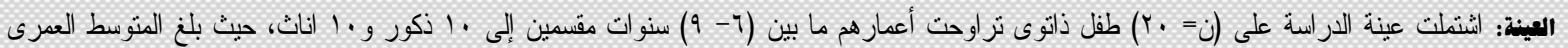

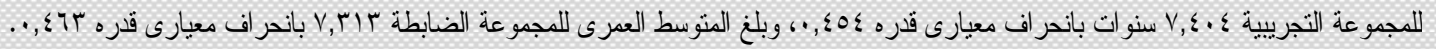

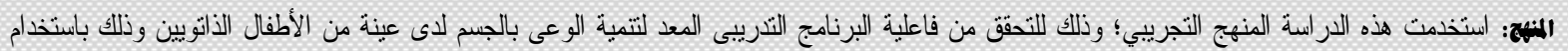

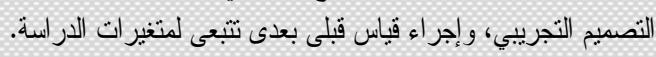

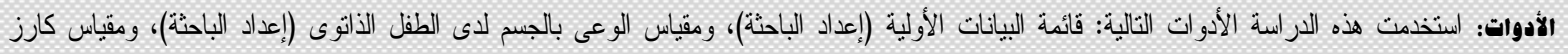

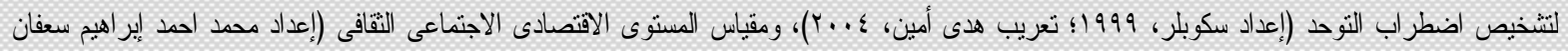

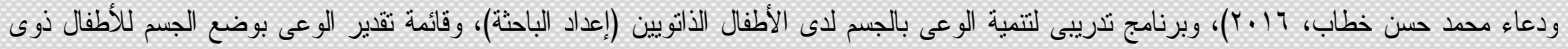

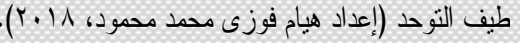

$$
\begin{aligned}
& \text { النتائج: أشتارت نتائج الدراسة إلى فاعلية البرنامج فى تتمبة الوعى بالجسم لاى عبنة من الأطفال الذاتو بين (المجو عة التجريبية). }
\end{aligned}
$$

\title{
The Effectiveness of A Training Program
}

\section{For Developing Body Awareness in A Sample of Autistic Children}

Problem: The study problem is determined in the following main question "What is the effectiveness of a training program for developing body awareness in a group of autistic children?" From this major question, the following minor questions are derived Are there any differences between average scores of the (experimental and control) group regarding the pre/post measurements of the program procedures on scale of body awareness?, Are there any differences between the average scores of the two groups (experimental and control) regarding the post- measurement of the program procedures on the scale of body awareness?, Are there any differences between average scores of the experimental group regarding the post/ follow up measurements of the program's procedures on the scale of body awareness?

Instruments: Primary Data List (by the researcher), The Self- Body Awareness Scale for Autistic Child (by the Researcher), Cars Scale for Diagnosing Autism Disorder (by Scopler, 1999; Arabized by Hoda Amin, 2004), A Training Program, for Developing Body Awareness of Autistic Children (by the researcher).

Objectives: This study drives at exploring the effectiveness of the training program in developing body awareness in a sample of autistic children, checking also the program's continuing impact on developing body awareness of the experimental group..

Method: This study uses the experimental method, using the experimental design, and the pre/ post/ follow up measurement.

Sample: It consists of 20 Male/ Female autistic children whose ages ranged between (6-9) yrs. old, divided into 10 males and 10 females, where the average age of the experimental group is 7.404 years with a standard deviation of 0.454 . The average age of the control group is 7.313 with a standard deviation of 0.463 . 
تهاف هذه الدراسة إلى الكثف عن فاعلية البرنامج التدريبى فى تتمية الوعى

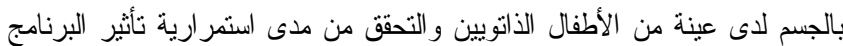
فى تنمية الوعى بالجسم لدى المجموعة التجريبية.

أهمية الدر اسلة:

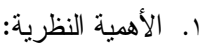

أ. تثقدم الاراسة الحالية تر اثا نظريا يوضح مفهوم الوعى بالجسم و النظريات

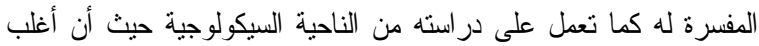
الدراسات التى ثتاولت هذا الدفهوم قامت بدر ستنه من منظور مجال التربية

الحركية.

ب. بالرغم من أن هناك العديد من الاراسات التى تتاولت البرامج الإرشادية

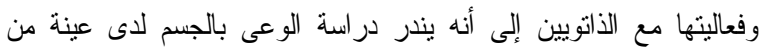

الأطفال الأتويين (فى حدود علم الباحثة).

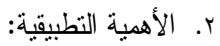
أ. تتمثل فى العمل على مساعدة الأطفال الأتويين من خلال تصميم برنامج إرشادى قائم على الوعى بالجسم التى تساعد على إدر الك أجز اء جسمه.

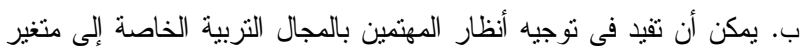
جديد نسبيا وهو الوعى بالجسم والذى يعتبر مؤشرا هاما لتعليم الأطفال

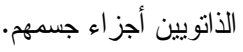

هذاهيم الدراسة: I الوعى بالجسم: مفهوم الوعى بالجسم هو إدرالك الفرد لبنائه الجسمى كأحد

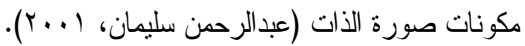

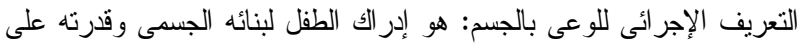

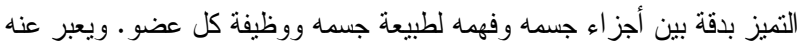

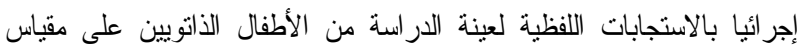
الوعى بالجسم (إعداد الباحثة). I الطفل الذاتوي: عرف ورولف (Wolff, 2005) أن الأطفال الذانت بيين يتسمون بضعف مهار ات تتاول الطعام (استعمال أدوات المائدة- مهار ات آداب الطعام)،

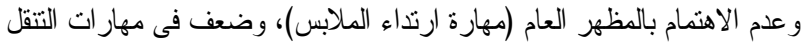

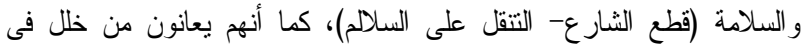
مهارات تقدير الذات (فهم الذات- العناية بالذات)، والمهارات الاجنماعية (التعامل

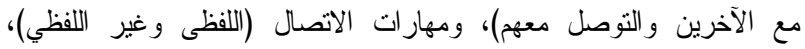

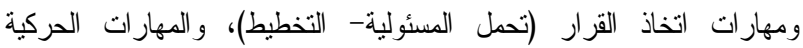

(التخطيط الحركى الجيد).

التعريف الإجر ائى للطفل الذاتوى: هم الأطفال الملتحقين بجمعية بسمة أمل لذوى

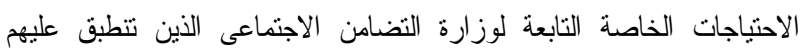

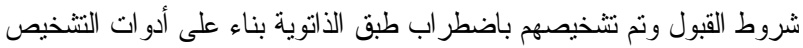

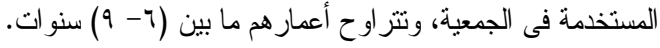

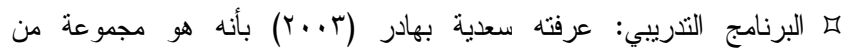

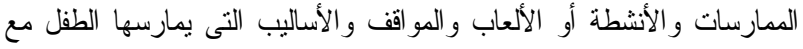

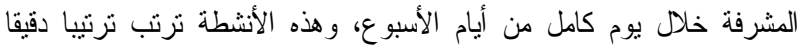

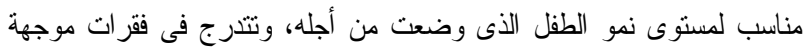

بحيث تفصل بين الفقرة و الأخرى فتر ات راحة ويسبق كل فترة تمهيد لها.

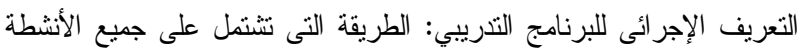

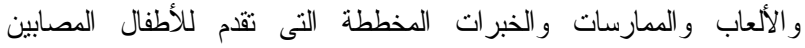
باضطر اب الأتوية خلال فترة زمنية محددة تهذف لنتمية الوعى بالجسم لايهم.

در اسات سابقة:

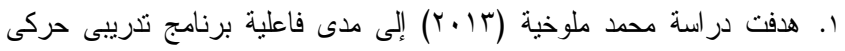

أصبحت رعاية ذوى الاحتياجات الخاصة أمر ا ملحا تحتمه الضرورة الاجتماعية و الإنسانية لكى يصبحون طاقة بناءة يمكن استغلالها و الإفادة منها. و إلا فأن الإعاقة تتعكس ويصبحون عو امل هدم ونتويه؛ لذلك يجب تدعيم الثقة فى قدر اتهم و الرعاية

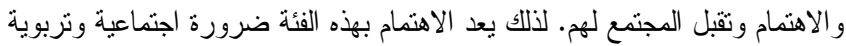

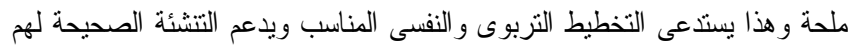
مما يجعل الطفل يلخل المجتمع بكل ثقة فى فهم أنه فرد فى جماعة عليه الالتزام

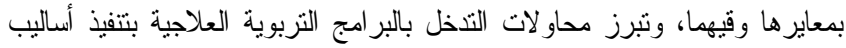

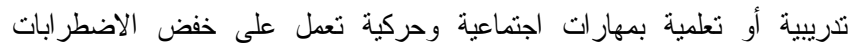

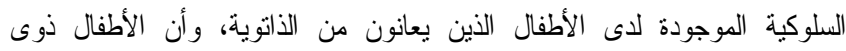

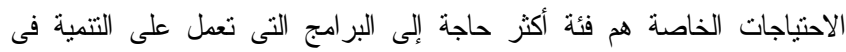
المجالات و المهار ات المختلفة، ويعتبر مفهوم الوعى بالجسم من المفاهيم التى نكون

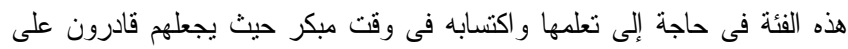

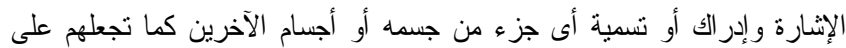
وعى بالمفاهيم المكانية المختلفة وتتمية كلا من التذكير والانتباه وذللك من خلال

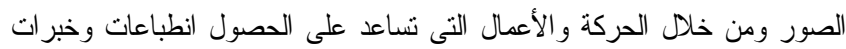
(الخبر ات الحس حركية) النى تساعد على تشكيل الوعى بالجسم. كما نجد أن الأطفال

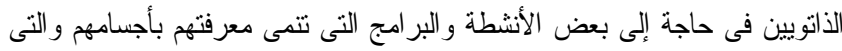
من شأنها أن تحقق معارف مختلفة.

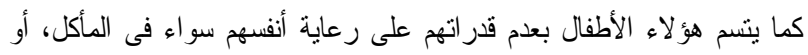

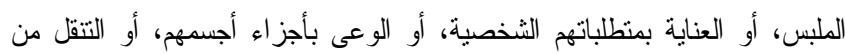

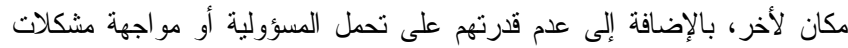

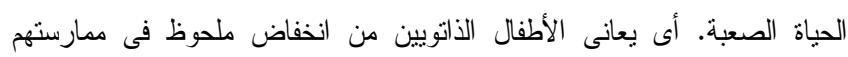

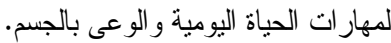
الذاتوية لبس اضطراب محددا ذات عرض معين وليس له تحاليل و اختبار ات

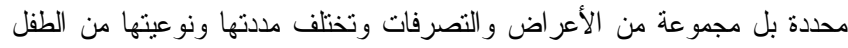
لآخر ، كما أنها تتفاوت فى الطفل نفسه وتختلف هذه الأعر اض لايه بالزيادة و النقصان

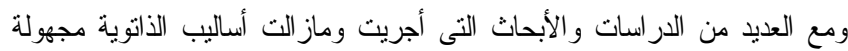

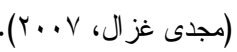

مثكلة الدر اسلة:

قد يفهم البعض أن المقصود بالوعى الجسمى هو تلك الصورة المرنبطة بمعرفة

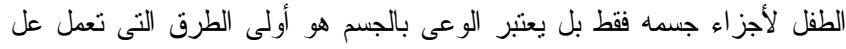

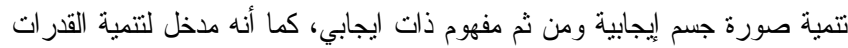
العقلية وبعد المهار ات الحباتبة المختلفة كالانتباه و التركيز و الحفظ و التفكير وممارسته لمو اقف الحياتية اليومية المختلفة، كما أنه يعمل على إدر الك الطفل للعلاقات المكانية

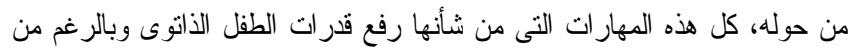

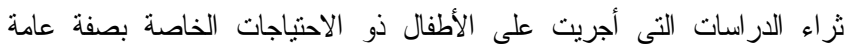

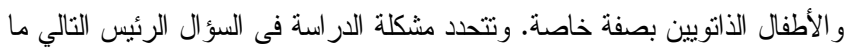

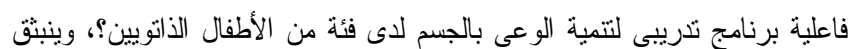
من هذا السؤال الرئيس الأسئلة الآتية: 1. هل توجد فروق بين متوسطات رثب درجات المجموعة التجريبية فى القياسين

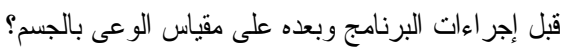

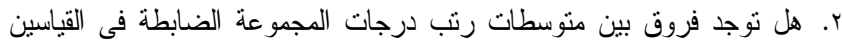

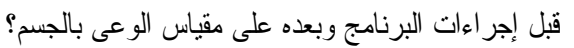

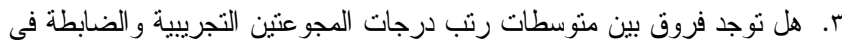

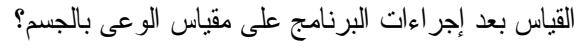

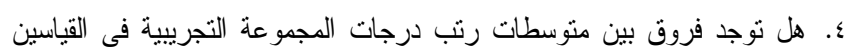

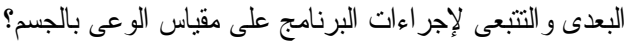


واستخدمت الدراسة مقياس تقدير التوحد التفولى (CARS)، ومقياس فاينلاند

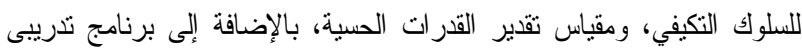

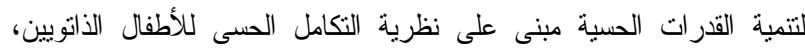

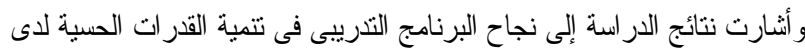

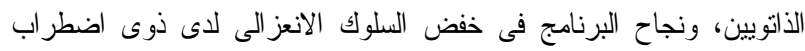
طيف النوحد.

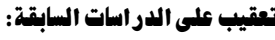

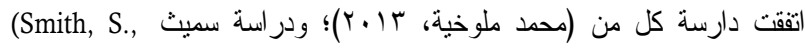

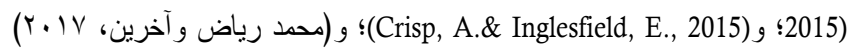
فى النتائج على إمكانية تعليم الأطفال الذاتويين أجزاء الجسم و الوعى به من خلا ولاد التفاعل المادى المناسب الخارجي.

فروض الدر اسة:

ا. توجد فروق ذات دلالة إحصائية بين منتسطات رتب درجات المجموعة

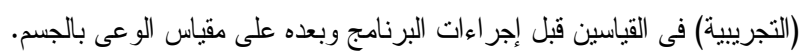

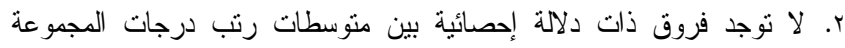

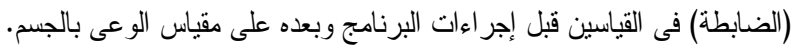

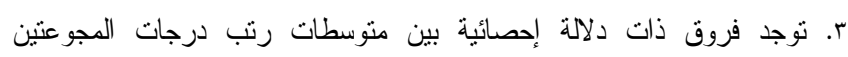

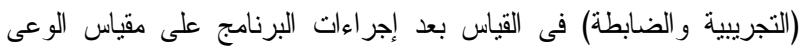

بالجسم.

ء. لا توجد فروق ذات دلالة إحصائية بين منوسطات رثب المجموعة (التجريبية)

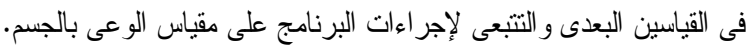

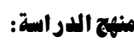

استخدمت هذه الدراسة المنهج التجريبي؛ وذللك للتحقق من فاعلية البرنامج التدريبى المعد لنتمية الوعى بالجسم لاى عينة من الأطفال الذانويين وذلك باستخدام

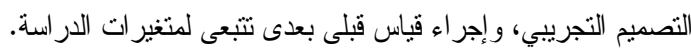

عينة الدر استة:

انشتملت عينة الدراسة على ·. ط طفل ذاتوى تراوحت أعمار هم ما بين (T- 9)

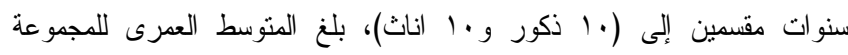

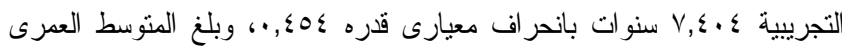

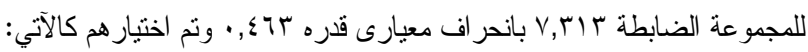
ا. أن تكون العينة من الأكور و الإناث.

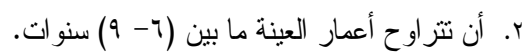

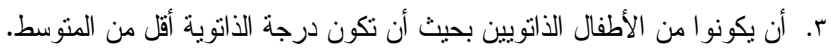

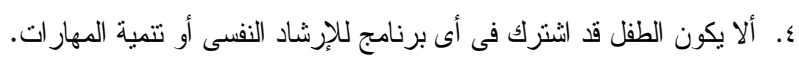
ه. أن يكونو ا متكافئين من حيث المستوى الاقتصادى و الاجتماعى و الثقافي.

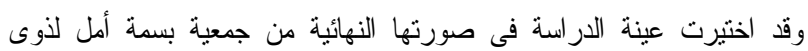

الاحتياجات الخاصة بمدينة نصر القاهرة.

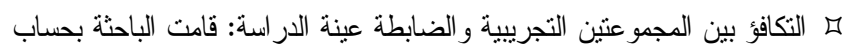
التكافؤ بين المجموعنين التجريبية والضابطة على متغيرات العمر، ودرجة

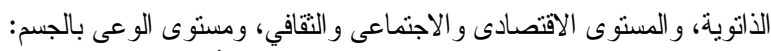

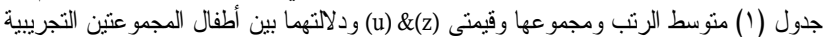

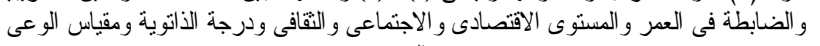

\begin{tabular}{|c|c|c|c|c|c|c|c|}
\hline \multirow{3}{*}{ الدسلة } & \multirow{3}{*}{$\begin{array}{l}\text { قيمة } \\
\text { (Z) }\end{array}$} & \multirow{3}{*}{ قيمة } & & \multirow{3}{*}{ لمجمو عة و اللا } \\
\hline & & & \multicolumn{2}{|c|}{ ضابطة (ن= • 1) } & \multicolumn{2}{|c|}{ تجرييية (ن= + 1) } & \\
\hline & & & رجبوع & متوسط & رجموع & رتوسط & \\
\hline 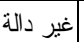 & - & $\leqslant \leqslant, \ldots$ & $99, \ldots$ & 9,9 . & $111, .$. & $11,1$. & العمر \\
\hline | غبر دالة &., $07 \mathrm{~V}$ & $\leqslant r, O$. & $9 \vee, 0$. & $9, v_{0}$ & $11 r, 0$. & $11, r_{0}$ & قتصادى و الاجنماعى و الثقافي \\
\hline |غبر دالة & $\cdot, \Lambda A Y$ & $r \Lambda, 0$. & 117,0 . & 11,70 & $94,0$. & $9, r_{0}$ & لنوحد الطفولة كارز \\
\hline | غير دالة & ., NAr & rл, o. & 1170. & 11.70 & $9 \uparrow, 0$. & $9, r_{0}$ & \\
\hline
\end{tabular}

لتتمية مهارات السلوك التكيفى وخفض السلوك النمطى لاى الطفل الذاتوي، و التحقق من مهارات السلوك التكيفى الأكثر شيوعا، ومدى فاعلية المهارات

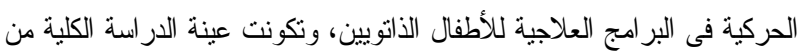

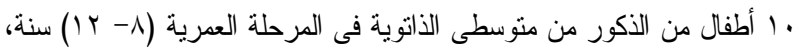

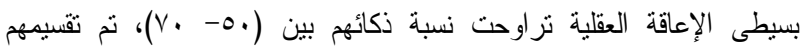

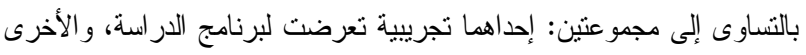

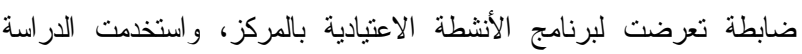

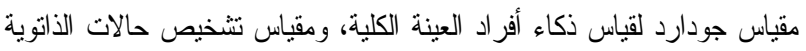

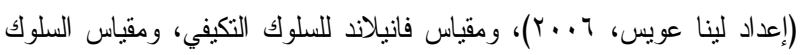

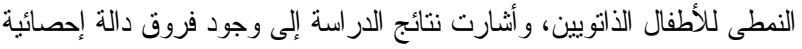
بين درجات أفر اد المجموعة التجريبية قبل وبعد تطبيق البرنامج على جميع أبعاد

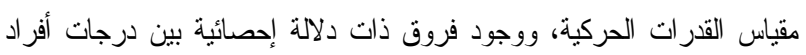

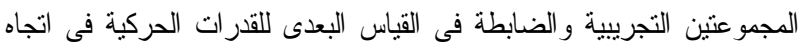
المجموعة التجريبية. r. دراسة سميث (Smith, 2015) بعنوان تأثرات برامج تتمية المهارات الحسية

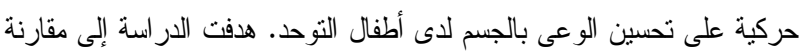

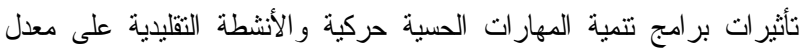

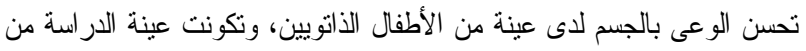

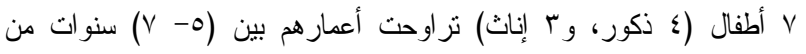

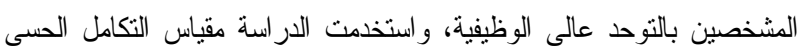

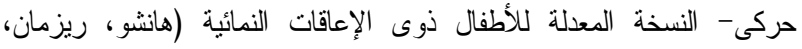

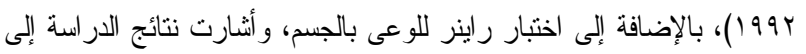

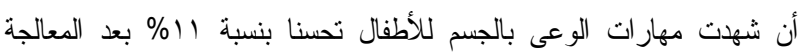
بالبرنامج الخاص بتتمية المهار ات الحسية حركية بالمقارنة مع الأنشطة النقليدية.

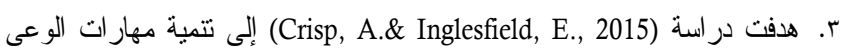
بالجسم كمؤشر على المهارات الحياتية و السلوك التكيفى للأطفال ذوى الإعاقات النمائية: در اسة مقارنة بين استر اتيجيات البرامج المكثفة وغير المكثقة، وتكونت

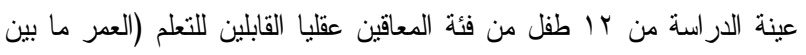

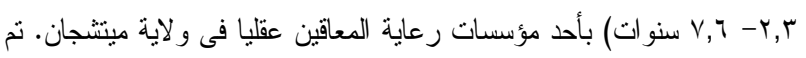
تقسيم الأطفال إلى مجموعتين منساويتين مجموعة تجريبية ضمت بادية 1 أطفال

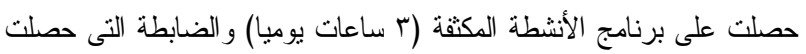

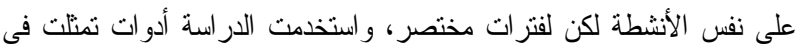

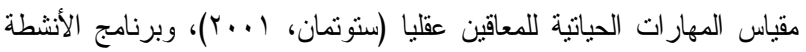

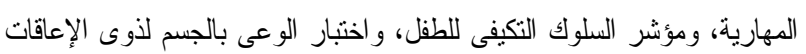

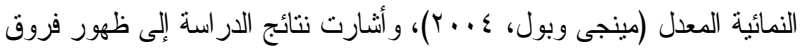

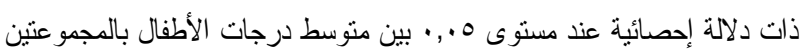

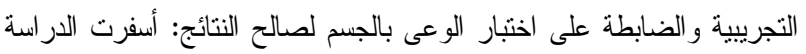

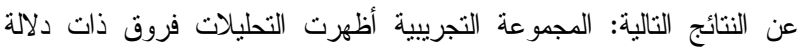
إحصائية عن مستوى 0 ., • بين متوسط درجات الأطفال بالمجمو عتين التجريبية

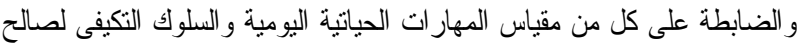

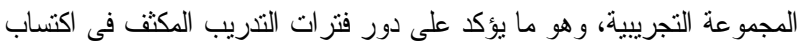
وثبات المهار ات الحياتية و السلوك التكيفى لأطفال المعاقين عقليا.

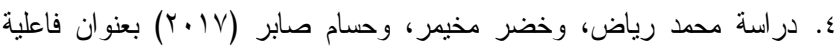

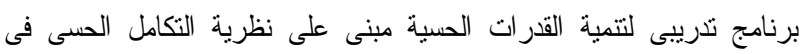

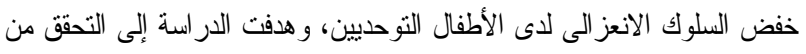

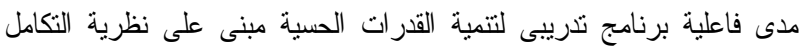

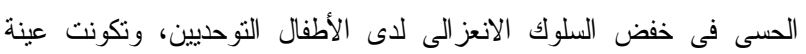

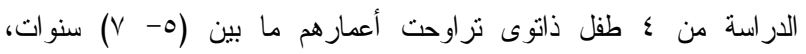


جدول (§) حساب الصدق المرنبط بالمحك بين درجات العينة على مقاس الوعى بالجسم لادى الطفل

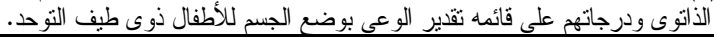

\begin{tabular}{|c|c|c|c|}
\hline مستوى الدلالة & معامل الارتباط & ن & المقياس \\
\hline \multirow{2}{*}{$\cdot, \cdot 1$} & \multirow{2}{*}{$\cdot, \lambda \leqslant Y$} & $r$. & مقياس الوعى بالجسم \\
\hline & & $r$. & قائمة نقيدر الوعى بوضع الجسم \\
\hline
\end{tabular}

يبين جدول (§) وجود ارتباط موجب دال إحصائيا بين درجات العينة

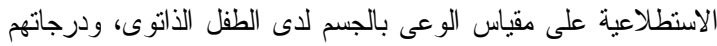

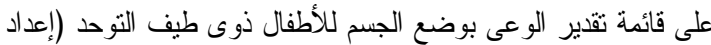

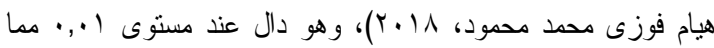

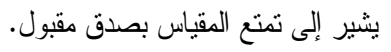

طريقة تطبيق أدوات الدر اسلة:

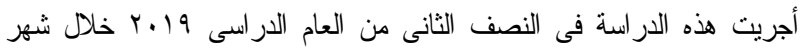
أغسطس وحتى نهاية شهر نوفمبر، حيث نم البدء باختيار العينة ثم المجانسة بين

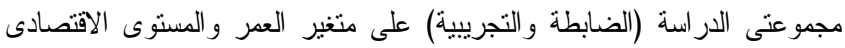
و الاجتماعى و الثقافى ودرجها الذانوية. ا. تم تطبيق مقياس الوعى بالجسم لدى الطفل الذاتوى مجمو عتى الدراسة (الضابطة، و التجريبية).

r. تم تطبيق برنامج إرشادى لنتمية الوعى بالجسم لاى الأطفال الذاتويين.

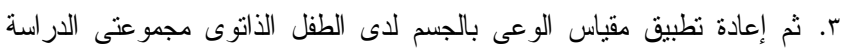

$$
\text { (الضابطة، و التجريبية). }
$$

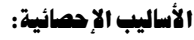

لحساب الكفاءة السيكومترية لمقباس الوعى بالجسم للأطفال الذانت يين وللتحقق من

صدق فروض الدراسة استخدمت الباحثة الأساليب الثالية: ه معادلة سبيرمان- براون لتصحيح طول المقياس فى ثبات التجزئة النصفية لمقياس الذكاء الاجتماعى للأطفال.

I معامل ألفا كرونباخ لحساب ثبات مقياس الوعى بالجسم للأطفال الذاتو يين.

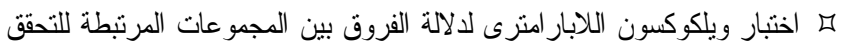

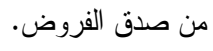

I اختبار مان ويتتى اللابار امترى لالالة الفروق بين المجموعات المسنقلة لحساب

$$
\text { التكافؤ بين المجمو عتين التجريبية و الضابطة. }
$$

نتائج الدر اسة:

I 17 نتائج الفرض الأول: ينص على "توجد فروق ذات دلالة إحصائية بين منوسطات

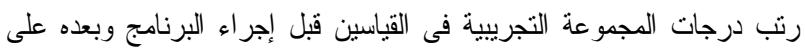

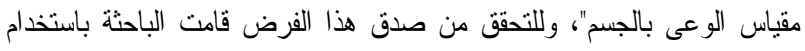
اختبار ولكوكسن Wilcoxon لإيجاد الفروق بين متوسطات رتب درب درجات أطفال

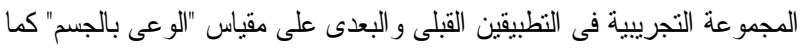

\begin{tabular}{|c|c|c|c|c|c|c|c|}
\hline الدعنوية & قيمة (Z) & مجموع الرتب & متوسط & الالنحراف & المتوسط & المجمو عة & المكون \\
\hline \multirow{2}{*}{$\cdot, \cdots v$} & \multirow{2}{*}{$r, Y \cdot P$} & $\cdot$ & $\cdot$ & 1,00 & 17,1 & تجرييية قبلي & \multirow{2}{*}{ المعرفي } \\
\hline & & «o & 0 & $r, \wedge \varepsilon$ & $r \cdot, \varepsilon$ & تجرييية بعدى & \\
\hline \multirow{2}{*}{$\therefore, \cdots$} & \multirow{2}{*}{ r,Aro } &. & . & $r, \varepsilon)$ & $1 \leqslant, V$ & تجرييية قبلي & \multirow{2}{*}{ السلوكي } \\
\hline & & 00 & 0,0 & $r, r q$ & $1 \lambda, \Lambda$ & تجرييية بعدى & \\
\hline \multirow{2}{*}{$\cdot, \ldots$} & \multirow{2}{*}{$r, \lambda \cdot q$} & . & . & $r, \cdot r$ & $r 1,0$ & تجرييية قبلي & \multirow{2}{*}{ لدرجة الكلية } \\
\hline & & 00 & 0,0 & $0, \varepsilon \pi$ & $r q, r$ & تجرييية بعدى & \\
\hline
\end{tabular}

يتضح من جدول (0): (0)

جدول (0) متو سطات الرتب ومجمو عها وقيمة (Z) ود لالتها بين القياسين قبل وبعد البرنامج

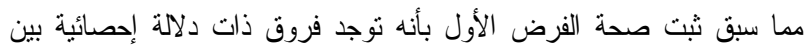

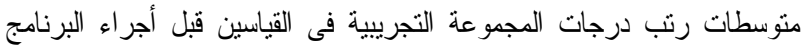

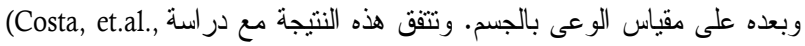
(Kayili, G.\& Ari, 2014)\& (Smith, S., 2015)
أشارت نتائج جدول (1) إلى عدم وجود فروق دالة إحصائيا بين متوسطات رتب

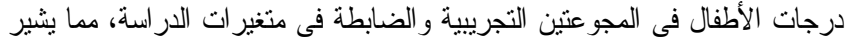

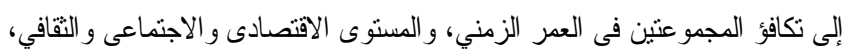
ودرجة الذانوية، ومستوى الوعى بالجسم.

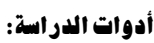

1. قائمة البيانات الأولية (إعداد الباحثة). r. مقياس الوعى بالجسم لدى الطفل الذاتوى (إعداد الباحثة).

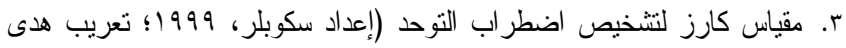

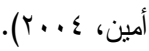

ء. مقياس المستوى الاقتصادى الاجتماعى الثقافى (إعداد محمد احد إبر اهيم سعفان

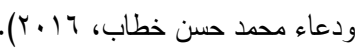

ه. برنامج تدريبى لتنمية الوعى بالجسم لدى الأطفال الذاتويين (إعداد الباحثة).

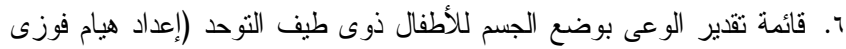

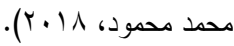

V. مقياس الوعى بالجسم لاى الطفل الذاتوى: أعدته الباحثة بهذف تقدير درجة الوعى بالجسم لاى الطفل الذاتوى، ولتوفير أداة سيكومترية مستمدة من البيئة العربية وخاصة البيئة المصرية، ليناسب خصائص وسمات الطفل الذاتوى عينة

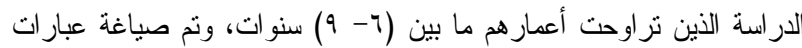

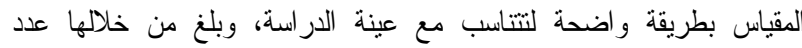
العبار ات المقياس فى صورته النهائية ؟ب عبارة. حساب الكفاءة السيكومنزية للمقياس:

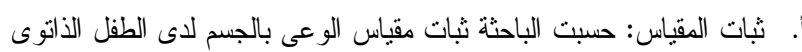

\begin{tabular}{|c|c|c|}
\hline 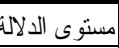 & 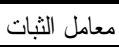 & طرق حساب الثبات \\
\hline.,$\cdot 1$ & $\cdot$, VAr & التجزئة النصفية بعد تصحيح طول المقياس بمعادلة سبيرمان- براون \\
\hline$\cdot, .1$ & $\cdot, 94 \wedge$ & ألفا كرونباخ \\
\hline
\end{tabular}

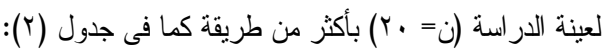

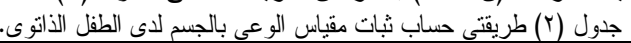

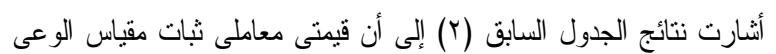
بالجسم لاى الطفل الذاتوى تشير إلى تمتع المقياس بثبات مقبول. ب. صدق المقياس: حسبت الباحثة صدق المقياس بطريقتين:

\begin{tabular}{|c|c|c|}
\hline معامل الصدق & \multicolumn{2}{|c|}{ أبعاد المقياس } \\
\hline$\star \star \star, 9 \vee 9$ & معامل ارتباط بيرسون & \multirow{2}{*}{ المكون المعرفي } \\
\hline$\cdot, \cdot, 1$ & الدلالة المعنوية & \\
\hline$\star \star,, \wedge \nsucc \wedge$ & معامل ارتباط بيرسون & \multirow{2}{*}{ المكون السلوكي } \\
\hline$\cdot, \ldots 1$ & الدلالة المعنوية & \\
\hline${ }^{\star \star} \cdot, 9 \Gamma \wedge$ & معامل ارتباط بيرسون & \multirow{2}{*}{ الدرجة الكلية } \\
\hline$\cdot, \cdots 1$ & الدلالة المعنوية & \\
\hline
\end{tabular}

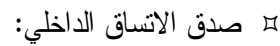

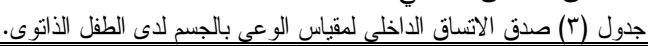

من الجدول السابق (r) لصدق الاتساق الاخلى السابق لمقياس الوعى لإبه بالجسم لاى الطفل الذاتوى نجد أن قيم معامل الارنباط دالة إحصائبا،

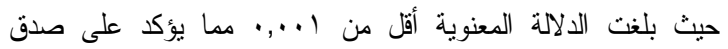
الاتساق الداخلى لأبعاد المقياس وبلغت قيم معامل الارنباط بيرسون بلهن

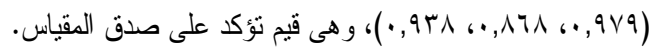
口 مدق المرتبط بالمحك: حسبت الباحثة الصدق المرتبط بالمحك، وذللك

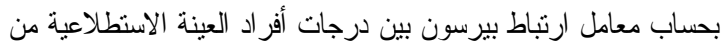

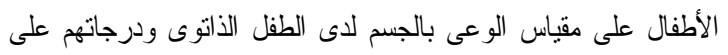
قائمه تقدير الوعى بوضع الجسم للأطفال ذوى طيف التوحد (إعداد هيام

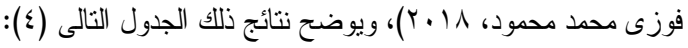


مما سبق ثبت صحة الفرض الثالث أنه توجد فروق ذات دلالة إحصائية بين

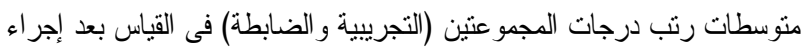

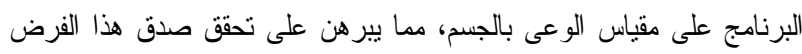

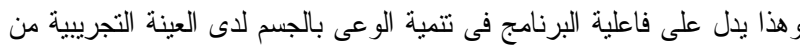

الأطفال الذاتويين.

I نتائج الفرض الر ابع: ينص على "لا نوجد فروق ذات دلالة إحصائية بين

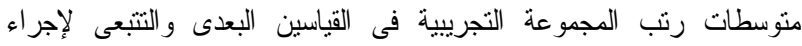

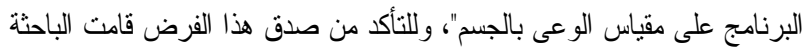

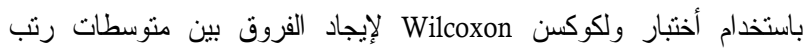
درجات أطفال المجموعة التجريبية فى النطبيقين البعدى و التتبعى على مقياس لإنداس

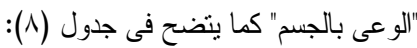

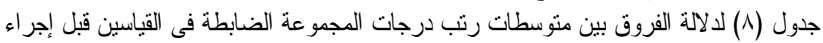

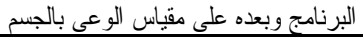

\begin{tabular}{|c|c|c|c|c|c|c|c|}
\hline المعنوية & قيمة (Z) & مجموع & متوسط & الالانحر اف & المنوسط & المجمو عة & المكون \\
\hline \multirow{2}{*}{$\cdot, 1$} & \multirow{2}{*}{$\cdots$} & 1,0 & 1,0 & $r, \wedge \leq$ & $r \cdot, \varepsilon$ & تجرييية بعدى & \multirow{2}{*}{ معرفي } \\
\hline & & 1,0 & 1,0 & $r, \wedge \varepsilon$ & $r \cdot, \varepsilon$ & تجرييية تتبعى & \\
\hline \multirow{2}{*}{$\cdot, 1$} & \multirow{2}{*}{$1, r \ldots$} & $\Lambda, 0$ & $r, \lambda r$ & & $1 \lambda, \Lambda$ & تجرييية بعدى & \multirow{2}{*}{ لسلوكي } \\
\hline & & 1,0 & 1,0 & $r, V \uparrow$ & $1 \Lambda, \varepsilon$ & تجريبية تتبعى & \\
\hline \multirow{2}{*}{. } & \multirow{2}{*}{$\cdot, 00 Y$} & 9,0 & r,IV & $0, \leqslant r$ & $r q, r$ & تجرييية بعدى & \multirow{2}{*}{ الكلية } \\
\hline & & 0,0 & $r, V_{0}$ & $0, \cdot 1$ & rq & تجريبية تتبعى & \\
\hline
\end{tabular}

مما سبق ثبت صحة الفرض الر ابع أنه لا توجد فروق ذات دلالة إحصائية بين

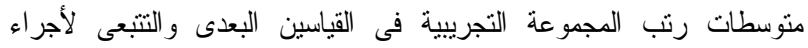

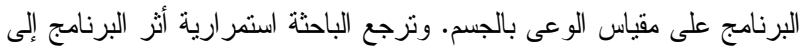

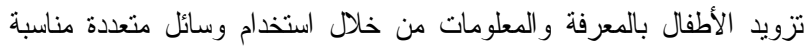

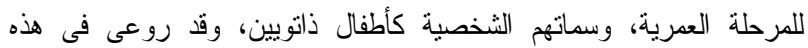

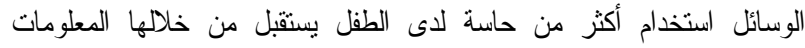

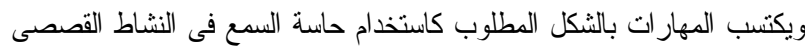

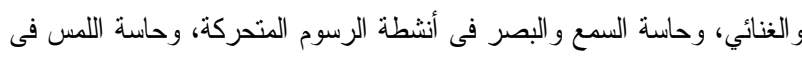

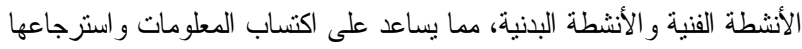
و انتقال أثر التعلم بشكل أكبر و أفضل.

توصيات الدراسة:

فى ضو ء ما توصلت إليه هذه الدر اسة من نتائج تقترح الباحثة التوصيات التاليه:

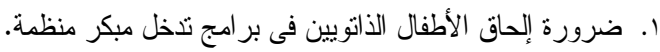

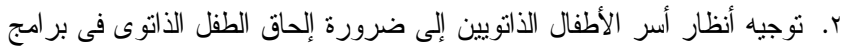

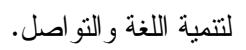

r. إعداد برامج تدريبية لتحسين الوعى بالجسم تلائم الأطفال الذاتويين فى مراحل

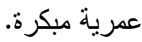

ع. إعداد بر امج إرشادية للو الدين حول كيفية التعامل مع الأبناء الذاتويين.

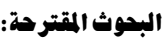

فى ضوء نتائج الدر اسات السابقة، وما أسفرت عنه هذه الدر اسة من نتائج، يمكن

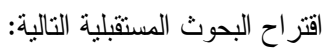

ا. العلاقة بين المعاملة الو الدية و الوعى بالجسم لاى الأطفال الذاتويين.

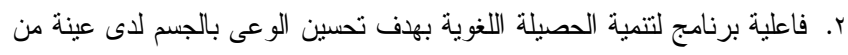
الأطفال الذاتوبين.

r. العلاقة بين الوعى بالجسم و التفاعل الاجتماعى لاى الأطفال الذاتويين.

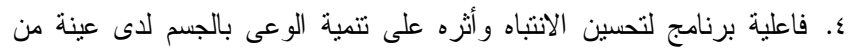
الأطفال الذانويين ذوى تشتت الانتباه وفرط الحركة.

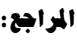

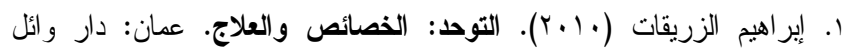

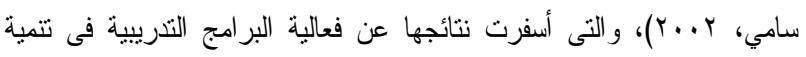

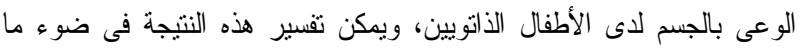

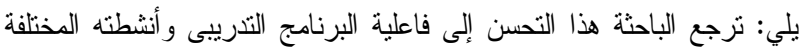

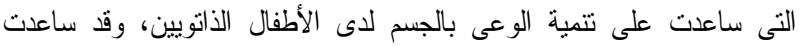
الأنشطة المتتوعة التى استخدمت فى البرنامج مع أطفال المجموعة التجريبية على تدريب الأطفال على قدرة الطفل على معرفة أجزاء جسمه وتسميتها،

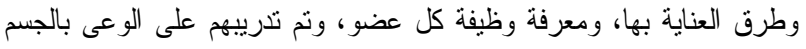

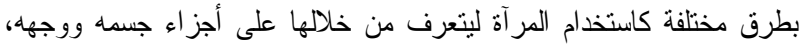
و استخدام البازل Puzzle و الذى ساعد الأطفال على وضع كل جزء من من أجزاء

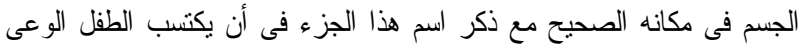

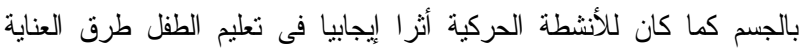

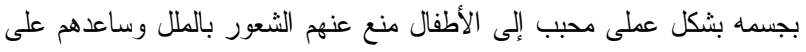

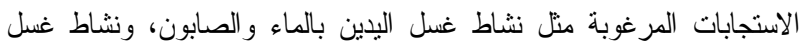

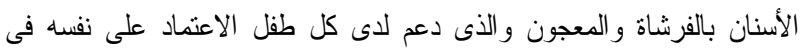
الرعاية الذاتية و الثأكيد على اكتساب عادات النظافة المطلوبة. I 17 نتائج الفرض الثاني: ينص على "لا توجد فروق ذات دلالة إحصائية بين متوسطات رتب درجات المجموعة الضابطة فى القياسين قبل إجراء البرنامج وبعده على مقياس الوعى بالجس"، وللتحقق من صدق هذا الفرض قامت الباحثة

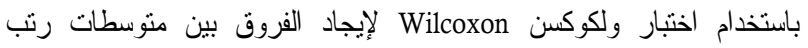

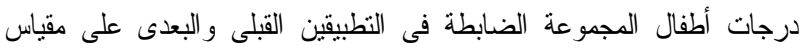
"اللوعى بالجسم". كما يتضح من جدول (؟) آ):

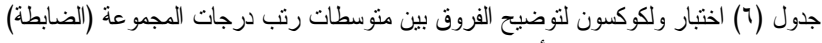

\begin{tabular}{|c|c|c|c|c|c|c|c|}
\hline الدعنوية & قيمة (Z) & مجموع & متوسط & الالنير اف & المنوسط & المجمو عة & المكون \\
\hline \multirow{2}{*}{$\cdot, \varepsilon$} & \multirow{2}{*}{$\cdot, 9.0-$} & Ir & $\varepsilon$ & $r, 11$ & $17, r$ & ضابطة قبلي & \multirow{2}{*}{ لمعرفي | لمع } \\
\hline & & $r \leq$ & $\varepsilon, \lambda$ & 1,9 & 17,7 & ضابطة بعدى & \\
\hline \multirow{2}{*}{$\cdot, \mathrm{V}$} & \multirow{2}{*}{ - שTr, - } & 9 & $\varepsilon, 0$ & $1, r 0$ & $10, \varepsilon$ & تجريبية قبلي & \multirow{2}{*}{ السلوكي } \\
\hline & & Ir & $r$ & $1, r 0$ & 10,0 & ضابطة قبلي & \\
\hline \multirow{2}{*}{$\cdot, 0$} & \multirow{2}{*}{ r,AlY - } & 00 & 0,0 & $r, 91$ & $\mathrm{r}, \mathrm{V}$ & ضابطة بعدى & \multirow{2}{*}{ الارلية } \\
\hline & & . & . & $r, Y_{0}$ & rr & ضابطة قبلى & \\
\hline
\end{tabular}

مما سبق ثبت صحة الفرض الثاني أنه لا نوجد فروق ذات دلالة إحصائية بين

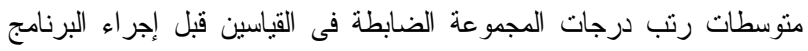

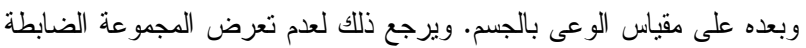

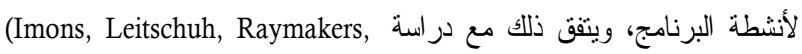

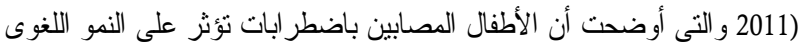
كاضطر اب الذاتوية تؤثر سلبا على الوعى بالجسم لاى هؤلاء الأطفال.

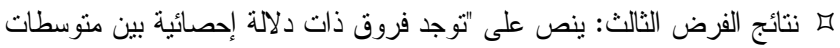
رثب درجات المجموعتين التجريبية والضابطة فى القياس بعد إجر اء البرنامج

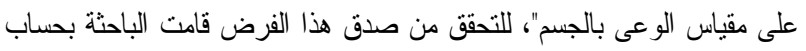

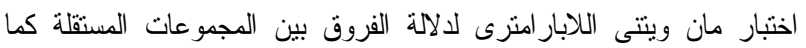

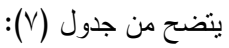

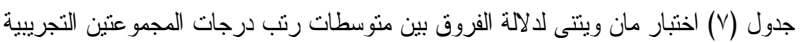

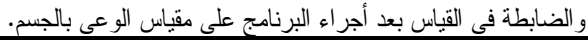

\begin{tabular}{|c|c|c|c|c|c|c|c|c|}
\hline الدعنوية & قيمة (Z) & قيمة (U) & مجموع الرتب & متوسط & المعياري & المتوسد & المجمو عة & المكون \\
\hline \multirow{2}{*}{$\cdot, \cdot r$} & \multirow{2}{*}{$\Upsilon, \wedge \wedge \varepsilon$} & \multirow{2}{*}{ ir } & $1 \leqslant, r$ & 1. & $r, \wedge \varepsilon$ & $r \cdot, \varepsilon$ & تجريبية بعدى & \multirow{2}{*}{ المعرفي } \\
\hline & & & $7, Y$ & 1. & 1,9 . & 17,7 & ضابطة بعدى & \\
\hline \multirow{2}{*}{$\cdot, \cdot r$} & \multirow{2}{*}{ T, YАY } & \multirow{2}{*}{ r. } & 15,0 & 1. & $r, r q$ & $\mid \Lambda, \Lambda$ & تجريبية بعدى & \multirow{2}{*}{ السلوكي } \\
\hline & & & $\mathrm{v}, \mathrm{O}$ & 1. & 1, ro & 10,0 & ضابطة بعدى & \\
\hline \multirow{2}{*}{$\cdot, \cdots v$} & \multirow{2}{*}{ r,707 } & \multirow{2}{*}{10} & $1 \varepsilon$ & 1. & $0, \varepsilon r$ & $r q, r$ & تجريبية بعدى & \multirow{2}{*}{ الالكلية } \\
\hline & & & v & 1. & r,Yo & rr & ضابطة بعدى & \\
\hline
\end{tabular}




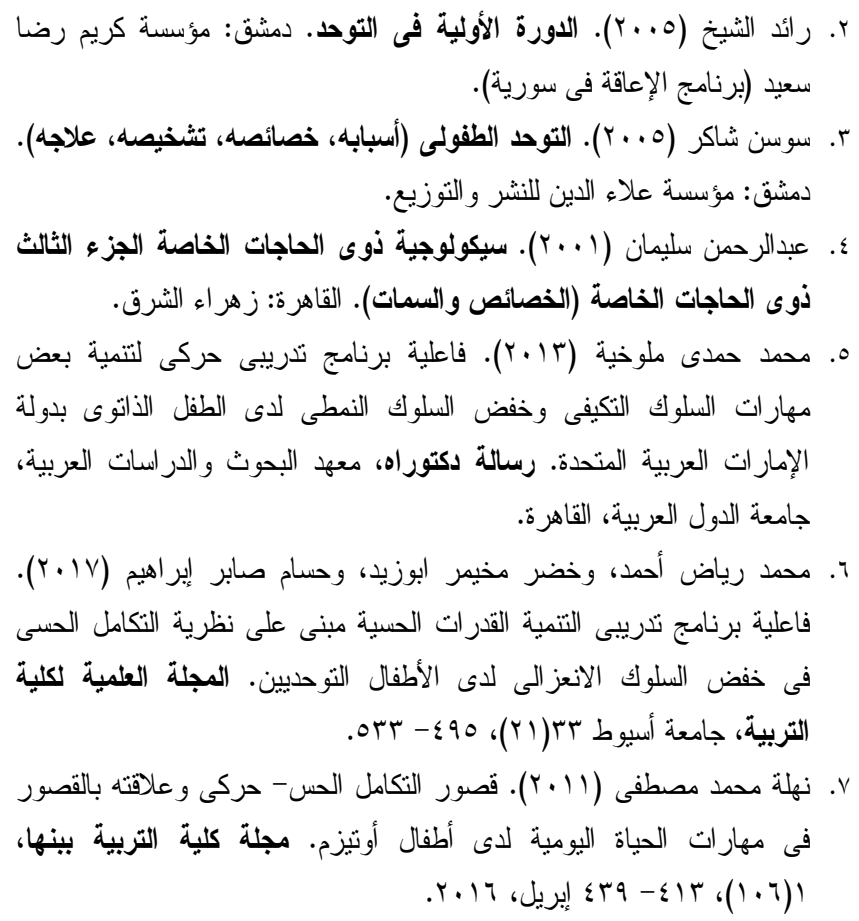

8. Crisp, A.\& Inglesfield, E. (2015). Development of Body Awareness As An Indicator of Life Skills And Adaptive Behavior To Developmentally Handicapped Children: A Comparison of Intensive and Non- Intensive Strategies. American Journal of Mental Deficiencies, 9(14).

9. Kayili, G.\& Ari, R. (2015). Educational Sciences: Theory\& Practice, 11(4), 2104- 2109.

10. Linden, P. (2002). Body Awareness Training for Children With Attention Deficit, Autism. New Delhi, India at Chaman offset, Delhi. 